\title{
Pengembangan Perangkat Pembelajaran Melalui Pemecahan Masalah untuk Meningkatkan Penalaran Matematis Mahasiswa Program Studi Pendidikan Matematika Jurusan PMIPA FKIP Universitas Riau
}

\author{
1Maimunah \\ 2Titi Solfitri \\ 3Putri Yuanita \\ 1,2,3 Program Studi Pendidikan Matematika FKIP Universitas Riau \\ Kampus Bina Widya KM 12,5 Simpang Baru, Pekanbaru 28293, Indonesia \\ E-mail: ${ }^{1}$ maimunahdra@yahoo.com
}

\begin{abstract}
Current learning and mathematical reasoning who have not been up, to be the reason to conduct research development. The desired product in this study is a learning device such as $R P$ and LKM to improve the mathematical reasoning through problem solving. Methode used such as Plomp and quality of the products developed by Nieveen. Assessment of product is the validity (validator), practicality, and effectiveness (results limited trial). Limited trial demonstrated the practicality criteria have been met as students respond positively to the learning, structure and step sequences of learning, interest in learning, and the LKS. Effectiveness criteria have been satisfied with either minimal category, or an increase of mathematical reasoning.
\end{abstract}

Keywords: Media of Learning, Mathematical Reasoning, Problem Solving.

\begin{abstract}
Abstrak
Pembelajaran saat ini dan penalaran matematis mahasiswa yang belum maksimal menjadi alasan untuk melakukan penelitian pengembangan. Produk yang dikehendaki dalam penelitian ini adalah perangkat pembelajaran yang terdiri dari RP dan LKM untuk meningkatkan penalaran matematis mahasiswa melalui pemecahan masalah. Tahapan pengembangan yang dilakukan mengikuti tahapan pengembangan Plomp dan kualitas produk yang dikembangkan menurut Nieveen. Penilaian pengembangan produk, yaitu kevalidan (validator), kepraktisan, dan keefektifan (hasil uji coba terbatas). Uji coba terbatas menunjukkan kriteria kepraktisan telah terpenuhi karena mahasiswa merespon positif terhadap suasana pembelajaran, urutan materi dan langkah pembelajaran, minat terhadap pembelajaran, dan LKM. Kriteria keefektifan telah terpenuhi dengan kategori minimal baik, atau terjadi peningkatan penalaran matematis mahasiswa.
\end{abstract}

Kata Kunci: Perangkat Pembelajaran, Penalaran Matematis, Pemecahan Masalah 


\section{Pendahuluan}

Perkuliahan di Program Studi Pendidikan Matematika seyogyanya merupakan sarana yang difungsikan untuk meningkatkan kemampuan penalaran matematis bagi mahasiswa calon guru. Hal ini dapat dilakukan dengan kegiatan pembelajaran melalui pemecahan masalah. Pembelajaran melalui pemecahan masalah adalah suatu kegiatan yang dimulai dengan penyajian masalah, selanjutnya melakukan investigasi penyelesaian masalah, mempresentasikan hasil penyelesaian masalah, dan mengevaluasi hasil penyelesaian masalah.

Masalah yang disajikan dapat terdiri dari masalah terstruktur atau masalah rutin, dan masalah tak terstruktur atau masalah non rutin. Suatu soal atau pertanyaan dikatakan masalah apabila soal atau pertanyaan tersebut menantang untuk dijawab, dan prosedur untuk menjawabnya tidak dapat dilakukan secara rutin ${ }^{1}$.

Pada umumnya mahasiswa telah memahami apa yang diinginkan dari soal atau permasalahan yang disajikan ${ }^{2}$. Akan tetapi sebagian besar mahasiswa lebih senang bekerja secara melalui contoh-contoh yang telah ada cara penyelesaiannya. Hal ini sesuai dengan pendapat Sa'dijah yang menyatakan bahwa peserta didik lebih menyukai menyelesaikan soal atau permasalahan yang sudah diketahui atau diberi tahu prosedur penyelesaian dari soal atau permasalahan tersebut ${ }^{3}$.

Beberapa penelitian pengembangan tentang pengembangan perangkat pembelajaran telah dilakukan sebelumnya. Dua diantaranya adalah tentang pengembangan perangkat pembelajaran berbasis pemecahan masalah berorientasi pada kemampuan penalaran dan komunikasi matematika yang dilakukan oleh Furdan Rahmadi ${ }^{4}$. Penelitian pengembangan tersebut menggunakan model pengembangan 3D (Define, Design, Develop) yang dilaksanakan di kelas X SMK Negeri 6 Yogyakarta. Dari hasil penelitian yang dilakukan yang dilakukan diperoleh bahwa perangkat pembelajaran yang

${ }^{1}$ Herman Hudojo, Pengembangan Kurikulum Dan Pembelajaran Matematika (Malang: Universitas Negeri Malang Press, 2005).

2 Maimunah, 'Model Pembelajaran Matematika Untuk Meningkatkan Kemampuan Penalaran Matematika Siswa', vol. November (Seminar Nasional Pendidikan, Sidoarjo: Universitas Muhammadiyah, 2013), 141-53.

3 Cholis Sa'dijah, 'Pengembangan Model Pembelajaran Matematika Beracuan Konstruktivisme Untuk Siswa SMP', Mathedu Jurnal Pendidikan Matematika. 1 (2) 1, no. 2 (July 2006): 109-22.

4 Furdan Rahmadi, 'Pengembangan Perangkat Pembelajaran Berbasis Pemecahan Masalah Berorientasi Pada Kemampuan Penalaran Dan Komunikasi Matematika', PYTHAGORAS: Jurnal Pendidikan Matematika 10, no. 2 (11 December 2015): 137-45, doi:10.21831/pg.v10i2.9133. 
meliputi RPP, LKS, dan THB adalah valid, praktis, dan efektif sehingga layak untuk digunakan. Penelitian pengembangan lainnya juga dilakukan oleh $\mathrm{Ni}$ Wayan Dian Permana Dewi dkk yang berusaha mengembangkan perangkat pembelajaran matematika dengan pendekatan scientific berorientasi teknologi informasi dan komunikasi untuk meningkatkan kemampuan pemecahan masalah dan penalaran siswa. Subjek penlitian tersebut adalah guru dan siswa SMK Kelas X Jurusan Teknologi Informasi dan Komunikasi pada SMK Negeri 2 Tabanan ${ }^{5}$. Hasil penelitian menunjukkan bahwa perangkat pembelajaran matematika dengan pendekatan scientific berorientasi Teknologi Informasi dan Komunikasi telah memenuhi kualitas valid, praktis, dan efektif.

Mata kuliah kalkulus diffrensial merupakan mata kuliah prasyarat untuk mengikuti matakuliah selanjutnya, khususnya matakuliah kalkulus integral, kalkulus multivariate, dan analisis real. Selain itu mata kuliah kalkulus differensial erat katannya dengan materi-materi yang ada pada pelajaran matematika di Sekolah Menengah Atas.

Berdasarkan hal tersebut maka sangat perlu untuk melakukan penelitian pengembangan, yang mengacu pada model pengembangan Plomp. Model ini terdiri dari tiga fase yaitu, fase investigasi awal, fase prototype, dan fase penilaian ${ }^{6}$. Kualitas model pengembangan mengacu pada Nieven yaitu, valid, praktis, dan efektif. Valid menurut ahli, praktis menurut mahasiswa, dan efektif menurut ketercapaian tujuan penelitian ${ }^{7}$.

${ }^{5}$ Ni Wayan Dian Permana Dewi, Prof Dr I. Gusti Putu Suharta, and Prof Dr I. Made Ardana, 'PENGEMBANGAN PERANGKAT PEMBELAJARAN MATEMATIKA DENGAN PENDEKATAN SCIENTIFIC BERORIENTASI TEKNOLOGI INFORMASI DAN KOMUNIKASI UNTUK MENINGKATKAN KEMAMPUAN PEMECAHAN MASALAH DAN PENALARAN SISWA', Jurnal Pendidikan Matematika 3, no. 1 (16 July 2014), http://pasca.undiksha.ac.id/ejournal/index.php/JPM/article/view/1365.

${ }^{6}$ Nienke Nieveen, 'Educational Design Researsh: An Introduction', in An Introduction to Educational Design Research (Educational Design Research, Shanghai: Netzodruk, n.d.), 89-102, http://www.slo.nl/downloads/2009/Introduction_20to_20education_20design_20research. pdf/download.

${ }^{7}$ Ibid. 


\section{Kerangka Teoretis}

Krulik, Rudnick, \& Milou menyatakan bahwa penalaran merupakan bagian dari kemampuan berpikir. Penalaran menurut Krulik, Rudnick, \& Milou terbagi atas empat tingkatan berpikir ${ }^{8}$. Tingkat pertama dari berpikir adalah tingkat mengingat (recall thinking). Tingkat kedua adalah penalaran yang terdiri dari berpikir dasar (basic thinking), berpikir kritis (critical thinking) dan berpikir kreatif (creative thinking). Berpikir dasar merupakan jenis berpikir berkaitan dengan pemahaman dan pengenalan konsep-konsep tertentu. Berpikir kritis (critical thinking) adalah berpikir yang melibatkan aktivitas menguji, menghubungkan dan mengevaluasi semua aspek dari sebuah situasi atau masalah. Selain itu, kemampuan untuk mengambil kesimpulan dari sekumpulan data yang diberikan dan menentukan inkonsistensi dan kontradiksinya. Berpikir kreatif merupakan berpikir yang bersifat asli dan reflektif, serta menghasilkan suatu produk yang kompleks. Aktivitas berpikir ini melibatkan pengsintesisan ide-ide, pembangunan ideide, perencanaan penerapan ide-ide dan penerapan ide-ide tersebut. Berpikir kritis dan berpikir kreatif termasuk dalam berpikir tingkat tinggi (higherorder) dan merupakan bagian dari penalaran.

Penalaran matematis meliputi: (1) mengumpulkan bukti-bukti, (2) membuat konjektur-konjektur, (3) menetapkan generalisasi-generalisasi, (4) membangun argumen-argumen, dan (5) menentukan kesimpulankesimpulan berdasarkan ide-ide dan hubungannya ${ }^{9}$. Ciri-ciri seseorang yang bernalar dan berpikir analitis adalah seseorang tersebut cenderung untuk menemukan pola dari keteraturan, membuat dugaan dan menyusun bukti. Disamping itu, mahasiswa yang memiliki penalaran yang baik dapat menggunakan data untuk mengajukan dugaan, menguji dugaan atau membuktikan dugaan tersebut ${ }^{10}$. Penalaran juga dapat dilakukan ketika mahasiswa, (1) menganalisis masalah, contoh: mengidentifikasi, mendefinisikan, memikirkan pola, mencari struktur yang tersembunyi, memikirkan kasus-kasus khusus, menerapkan konsep awal siswa, membuat deduksi dan dugaan awal, dan memutuskan pendekatan yang sesuai, (2) mengimplementasikan strategi, contoh: membuat prosedur tertentu, mengorganisasikan solusi, membuat deduksi logis, memonitoring solusi, (3)

${ }^{8}$ Stephen Krulik, Jesse A Rudnick, and Eric Milou, Teaching Mathematic in the Middle School (USA: Pearson, 2003).

9 Rochmad, 'Pengembangan Model Pembelajaran Matematika Beracuan Konstruktivisme Yang Melibatkan Pola Pikir Induktif-Deduktif Untuk Siswa Smp/Mts' (Universitas Negeri Surabaya, 2009).

10 Toni Scusa and Yuma, Five Processes of Mathematical Thinking: Math in the Middle Institute Partnership (Lincoln: University Of Nebraska, 2008). 
mencari dan menggunakan koneksi, dan (4) merefleksi solusi, contoh: interpretasi solusi, memikirkan solusi yang rasional, melihat kembali asumsi awal, menjustifikasi atau memvalidasi solusi, melihat cara yang berbeda, memperhalus argumen, dan menggenaralisasi solusi.

Berdasarkan penjelasan di atas maka penalaran matematis dalam penelitian ini adalah kemampuan mahasiswa untuk merumuskan kesimpulan atau pernyataan baru berdasarkan beberapa pernyataan yang kebenarannya telah dibuktikan atau diasumsikan sebelumnya. Indikator kemampuan penalaran matematis dalam penelitian ini adalah: (1) memahami masalah, (2) melakukan manipulasi matematika, dan (4) menarik kesimpulan

Pemecahan masalah, menurut Lynch dan Star adalah jika mahasiswa diberikan masalah, maka mereka akan berusaha untuk menyelesaikan masalah dengan cara yang telah mereka ketahui ${ }^{11}$. Penalaran matematis terjadi jika disajikan masalah di awal pembelajaran, maka akan memaksa mereka bernalar. Bagi mahasiswa yang mengalami kesulitan dalam menyelesaikan masalah, maka mereka memerlukan bantuan baik dari teman sekelompoknya maupun dosen. Dalam berdiskusi mahasiswa melakukan penyelidikan. Penyelidikan yang dilakukan dapat menjembatani penalaran matematis mahasiswa ${ }^{12}$. Penyelidikan atau investigasi ini dilakukan secara kooperatif. Kelompok kooperatif yang dibentuk terdiri dari mahasiswa dengan kemampuan rendah, sedang, dan tinggi ${ }^{13}$.

Dalam kaitannya dengan pengembangan perangkat pembelajaran, Plomp menunjukkan suatu model yang bersifat lebih umum dalam merancang pendidikan (termasuk pembelajaran). Model ini terdiri dari tiga fase yaitu, fase investigasi awal (preliminary research phase), fase prototipe ( prototyping phase), dan fase penilaian (assesment phase) ${ }^{14}$.

Pengembangan perangkat pembelajaran dimulai dari menelaah isi mata kuliah kalkulus differensial khususnya untuk sub materi turunan, perangkat pembelajaran berupa RP dan LKM, dan model pembelajaran yang sedang berlangsung saat ini. RP merupakan suatu pedoman langkah-langkah kegiatan pembelajaran, dan LKM merupakan lembar panduan bagi mahasiswa untuk melakukan aktivitas seperti menyelesaikan masalah,

11 Kathleen Lynch and Jon R Star, 'Views of Struggling Students on Instruction Incorporating Multiple Strategies in Algebra I: An Exploratory Study' 45, no. 1 (January 2014): 6-18, doi:10.5951/jresematheduc.45.1.0006.

12 Merrilyn Goos, 'Learning Mathematics in a Classroom Community of Inquiry', Journal for Research in Mathematics Education 35, no. 4 (July 2004): 256-91.

${ }^{13}$ Robert E Slavin, Psikologi Pendidikan Teori Dan Praktek(Jakarta: PT. Indeks, 2008).

14 Tjeerd Plomp, 'Educational Design Researsh: An Introduction', in An Introduction to Educational Design Research (Educational Design Research, Shanghai: Netzodruk, 2013), 936, http://www.slo.nl/downloads/2009/Introduction_20to_20education_20design_20research.pdf/download. 
mengungkapkan penalaran matematis, dan mengevaluasi penalaran matematis mahasiswa. Selanjutnya perancangan prototype ini divalidasi. Perangkat yang telah divalidasi selanjutnya diuji cobakan. Uji coba yang dilakukan pada penelitian ini adalah uji coba terbatas. Hasil uji coba dilakukan untuk melihat apakah perangkat tersebut bersifat peraktis dan efektif.

\section{Metode Penelitian}

Lokasi penelitian ini di program studi pendidikan matematika Jurusan Pendidikan MIPA FKIP Universitas Riau. Subjek penelitian ini adalah mahasiswa pendidikan matematika yang mengikuti perkuliahan kalkulus diferensial.

Jenis data dan sumber data dapat disarikan pada Tabel 1 berikut.

Tabel. 1 Jenis Data dan Sumber Data

\begin{tabular}{|c|l|c|}
\hline No & \multicolumn{1}{|c|}{ Jenis Data } & Sumber Data \\
\hline 1 & Kevalidan Perangkat & Validator \\
\hline 2 & Kevalidan Instrumen & Validator \\
\hline 3 & Kepraktisan Perangkat & Mahasiswa \\
\hline 4 & Keefektifan Perangkat & Mahasiswa \\
\hline
\end{tabular}

Fase-fase pengembangan secara berturut-turut diuraikan tentang fase investigasi awal (preliminary research), fase prototipe (prototyping phase), dan fase penilaian (assessment phase) adalah sebagai berikut, 1. Fase Investigasi Awal (Preliminary Research)

Investigasi awal melalui pemecahan masalah untuk mengembangkan penalaran matematis mahasiswa meliputi dua hal, yaitu investigasi awal tentang penalaran matematis mahasiswa dan perangkat pembelajaran.

2. Fase Prototipe (Prototyping Phase)

Pada fase-2 disusun perangkat pembelajaran melalui strategi pemecahan masalah dan instrumen penilaian. Perangkat-perangkat yang disusun adalah rencana pembelajaran (RP), dan lembar kegiatan mahasiswa (LKM). Instrumen-instrumen untuk mengukur kevalidan, kepraktisan, dan keefektifan disusun dalam fase ini. Pada fase ini disusun lembar validasi, angket respon mahasiswa dan tes formatif. Untuk instrument Kevalidan disusun: (1) lembar validasi RP, (2) lembar validasi LKM, (3) lembar validasi $\mathrm{TF}$, (4) lembar validasi angket respon mahasiswa, untuk instrumen kepraktisan disususn: Angker respon mahasiswa, dan untuk instrumen keefektifan disusun: Tes Formatif 
3. Fase Penilaian (Assessment Phase)

Aktivitas-aktivitas difokuskan pada fase ini adalah mengadakan uji coba lapangan. Aktivitas uji coba lapangan bertujuan untuk mengetahui perangkat-perangkat yang dikembangkan (prototite yang telah dinyatakan valid) telah memenuhi kriteria kepraktisan dan keefektifan

\section{Hasil Penyusunan Perangkat dan Instrumen}

Hasil penyusunan perangkat pembelajaran berupa rencana pembelajaran (RP), dan lembar kegiatan mahasiswa (LKM), diuraikan sebagai berikut

1. Rencana Pembelajaran (RP)

Penyusunan RP dibatasi pada satu materi pokok, yakni materi turunan yang terdiri dari 4 (empat) RP dengan alokasi seperti pada Tabel 2 berikut.

Tabel 2 Rincian Rencana Pembelajaran (RP)

\begin{tabular}{|c|l|c|c|}
\hline Pert ke & \multicolumn{1}{|c|}{ Materi Pembelajaran } & Waktu & Jml RP \\
\hline 1. & Turunan di satu titik dan turunan sepihak & $3 \times 50$ menit & 1 \\
\hline 2. & $\begin{array}{l}\text { Fungsi turunan pertama dan rumus-rumus } \\
\text { turunan }\end{array}$ & $3 \times 50$ menit & 1 \\
\hline 3. & $\begin{array}{l}\text { Turunan fungsi koposisi, fungsi invers, dan } \\
\text { turunan ke-n }\end{array}$ & $3 \times 50$ menit & 1 \\
\hline 4. & $\begin{array}{l}\text { Turunan fungsi implicit dan parameter, dan } \\
\text { persamaan garis singgung dan garis normal }\end{array}$ & $3 \times 50$ menit & 1 \\
\hline
\end{tabular}

\section{Lembar Kegiatan Mahasiswa (LKM)}

Penyajian LKM yang dihasilkan memuat aktivitas sebagai tempat mahasiswa bekerja agar dapat mengembangkan penalaran matematis mahasiswa.

Hasil penyusunan instrumen untuk memutuskan apakah perangkat bersifat valid, praktis dan efektif, meliputi tiga macam, yaitu instrumen kevalidan, instrumen kepraktisan, dan instrumen keefektifan.

1. Instrumen Kevalidan

Instrumen-instrumen kevalidan tersebut adalah: (a) lembar validasi Lembar Rencana Pembelajaran (RP), (b) lembar validasi Lembar Kegiatan Mahasiswa (LKM), (c) lembar validasi Lembar Angket Respon Mahasiswa (ARM), dan (d) lembar validasi Tes Formatif (TF).

2. Instrumen Kepraktisan

Instrumen-instrumen kepraktisan yang dihasilkan dari lembar angket respon mahasiswa (ARM). 
3. Instrumen Keefektifan

Instrumen keefektifan adalah tes formatif (TF) yang digunakan untuk mengukur kemampuan penalaran matematis mahasiswa.

\section{Hasil Validasi Perangkat dan Instrumen}

1. Hasil Validasi RP

Kevalidan RP dinilai oleh tiga orang validator. Nilai rata-rata keseluruhan aspek yaitu, $V_{a}=3,67$, Jika dirujuk pada penentuan kriteria kevalidan RP, maka RP yang dikembangkan memiliki kriteria valid.

Beberapa catatan yang diperoleh dari ahli untuk perbaikan perangkat pembelajaran seperti pada Tabel 3 berikut.

Tabel 3 Revisi Hasil Validasi RP

\begin{tabular}{|c|l|l|}
\hline No & \multicolumn{1}{|c|}{ Sebelum Revisi } & Setelah Revisi \\
\hline 1. & RP singkat dan kaku & Sudah diperbaiki \\
\hline 2. & $\begin{array}{l}\text { Belum sesuai antara pertanyaan } \\
\text { dengan tujuan penelitian }\end{array}$ & Sudah diperbaiki \\
\hline 3. & $\begin{array}{l}\text { Pengorganisasian kelompok } \\
\text { berdasarkan apa }\end{array}$ & Sudah diperbaiki \\
\hline 4. & Sesuaikan antara RP dengan TF & Sudah diperbaiki \\
\hline
\end{tabular}

2. Hasil validasi LKM

Kevalidan LKM dinilai oleh tiga orang validator. Ketiga validator memberikan nilai pada lembar validasi LKM yang telah disediakan dan memberikan catatan saran/masukan untuk perbaikan. Rata-rata nilai pernyataan untuk setiap aspek penilaian kevalidan LKM adalah $V_{a}=3,11$, maka LKM yang dikembangkan memiliki kriteria valid. Tael 4 berikut merupakan beberapa catatan dari validator

Tabel 4 Revisi Hasil Validasi LKM

\begin{tabular}{|c|l|c|}
\hline No & \multicolumn{1}{|c|}{ Sebelum Revisi } & Setelah Revisi \\
\hline 1. & $\begin{array}{l}\text { Aktivitas pada LKM belum menggambarkan } \\
\text { penalaran matematis }\end{array}$ & Sudah diperbaiki \\
\hline 2. & $\begin{array}{l}\text { Materi prasyarat perlu dicantumkan dalam } \\
\text { LKM untuk mendukung penyelesaian } \\
\text { masalah }\end{array}$ & Sudah diperbaiki \\
\hline
\end{tabular}

3. Hasil validasi ARM

Kevalidan ARM dinilai oleh tiga orang validator. Ketiga validator memberikan nilai pada lembar validasi ARM yang telah disediakan dan memberikan catatan masukan untuk perbaikan. Rata-rata nilai untuk setiap aspek penilaian kevalidan ARM adalah $V_{a}=3,22$. Beberapa catatan yang diperoleh dari ahli untuk perbaikan ARM seperti pada Tabel 5 berikut. 
Tabel 5 Revisi Hasil Validasi ARM

\begin{tabular}{|c|l|l|}
\hline No & \multicolumn{1}{|c|}{ Sebelum Revisi } & Setelah Revisi \\
\hline 1. & Pernyataan dalam ARM & Sudah diperbaiki \\
\hline 2. & Samakan skala penilaian & Sudah diperbaiki \\
\hline
\end{tabular}

4. Hasil validasi TF

Kevalidan TF dinilai oleh tiga orang validator. Rata-rata nilai untuk setiap aspek penilaian kevalidan TF adalah $V_{a}=4,00$. Maka TF yang dikembangkan memiliki kriteria valid. Beberapa catatan yang diperoleh dari ahli untuk perbaikan TF dilihat pada Tabel 6 berikut.

Tabel 6 Revisi Hasil Validasi TF

\begin{tabular}{|c|l|l|}
\hline No & Sebelum Revisi & Setelah Revisi \\
\hline 1. & Indikator penalarannya & Sudah diperbaiki \\
\hline 2. & Perbaiki masalahnya & Sudah diperbaiki \\
\hline 3. & Periksa butir tes & Sudah diperbaiki \\
\hline
\end{tabular}

\section{Hasil Uji Coba Perangkat}

Pelaksanan uji coba dilakukan sebanyak 4 (empat) kali pertemuan sesuai dengan banyaknya RP yang disediakan. Hasil-hasil yang dicapai pada uji coba terbatas adalah hasil penyajian data kepraktisan, dan keefektifan perangkat.

1. Hasil penyajian data kepraktisan

Berikut akan disajikan rekap rata-rata dari angket respon mahasiswa seperti pada Tabel 7 berikut.

Tabel 7 Hasil ARM pada Uji Coba Terbatas

\begin{tabular}{|l|l|l|}
\hline No & Aspek Terhadap & Respon \\
\hline 1 & Suasana Pembelajaran & Positif \\
\hline 2 & $\begin{array}{l}\text { Urutan Materi dan Langkah } \\
\text { Pembelajaran }\end{array}$ & Positif \\
\hline 3 & $\begin{array}{l}\text { Minat terhadap Pembelajaran } \\
4\end{array}$ & Positif \\
\hline
\end{tabular}

Rata-rata keseluruhan respon mahasiswa dapat disimpulkan bahwa respon mahasiswa terhadap suasana pembelajaran, urutan materi dan langkah pembelajaran, minat terhadap pembelajaran, dan LKM adalah positif. Berdasarkan respon tersebut dapat disimpulkan bahwa pelaksanaan pembelajaran positif. 
2. Hasil penyajian data keefektifan

Data keefektifan perangkat pembelajaran adalah data peningkatan penalaran matematis mahasiswa yang diperoleh dari TF pada uji coba terbatas. seperti pada Tabel 8 berikut.

Tabel 8 Hasil Tes Fomatif pada Uji Coba Terbatas

\begin{tabular}{|l|l|c|c|}
\hline No & Kode Mahasiswa & Rata-rata Hasil Tes & Kriteria \\
\hline 1 & Mahasiswa 1 & 67,5 & Baik \\
\hline 2 & Mahasiswa 2 & 65 & Baik \\
\hline 3 & Mahasiswa 3 & 67,5 & Baik \\
\hline 4 & Mahasiswa 4 & 67 & Baik \\
\hline 5 & Mahasiswa 5 & 65 & Baik \\
\hline 6 & Mahasiswa 6 & 67,5 & Baik \\
\hline 7 & Mahasiswa 7 & 75 & Baik \\
\hline 8 & Mahasiswa 8 & 75 & Baik \\
\hline 9 & Mahasiswa 9 & 65 & Baik \\
\hline 10 & Mahasiswa 10 & 67 & Baik \\
\hline 11 & Mahasiswa 11 & 65 & Baik \\
\hline 12 & Mahasiswa 12 & 70 & Baik \\
\hline 13 & Mahasiswa 13 & 70 & Baik \\
\hline 14 & Mahasiswa 14 & 85 & Sangat Baik \\
\hline
\end{tabular}

Hasil uji coba terbatas menunjukkan bahwa terdapat 13 orang mahasiswa dengan hasil baik dan satu orang mahasiswa memperoleh hasil sangat baik Berdasarkan hasil uji coba tersebut, maka dapat disimpulkan bahwa hasil analisis keefektifan berada pada kategori minimal baik.

Berdasarkan hasil validasi dan uji coba terbatas maka dapat disimpulkan bahwa perangkat pembelajaran yang dikembangkan telah memenuhi kevalidan, kepraktisan, dan keefektifan.

Aspek-aspek yang belum terlaksana dengan baik pada uji coba terbatas adalah sebagai berikut.

1. Waktu yang digunakan mahasiswa lebih banyak tersita saat mahasiswa melakukan investigasi sehingga presentasi hasil menjadi berkurang.

2. Mahasiswa lebih banyak memerlukan bantuan dosendalam penyelesaian masalah.

3. Mahasiswa masih membaca hasil penyelesaian masalah, bukan menjelaskanya.

4. Mahasiswa masih ragu-ragu dalam melakukan aktivitas manipulasi matematika. 


\section{Penutup}

Produk yang dikembangkan telah memenuhi kriteria kevalidan, kepraktisan, dan keefektifan. Kelebihan produk ini terletak pada perangkat pembelajaran yang telah disusun melalui strategi pemecaham masalah. Berikut kesimpulan tentang kelebihan perangkat pembelajaran yang dikembangkan, dan saran-saran.

1. Kelebihan RP

Beberapa kelebihan RP adalah:

a. RP yang telah dikembangkan melalui strategi pemecahan masalah menginginkan mahasiswa terlibat secara aktif dalam kelompoknya dalam menyelesaikan masalah. Hal ini bertujuan agar ketika mahasiswa berdiskusi, dan bekerjasama maka mahasiswa tersebut telah memiliki pengetahuan untuk didiskusikan. Peran dosen tidak terlalu dominan dalam strategi ini. Karena dosen bertindak sebagai motivator, fasilitator, dan moderator. Sedangkan jika dosen tidak menggunakan RP, maka dosen cenderung mendominasi kelas, dan mahasiswa menerima secara pasif.

b. RP yang dikembangkan bertujuan untuk meningkatkan penalaran matematis mahasiswa, secara langsung meningkatkan penguasaan materi.

2. Kelebihan LKM

LKM yang berhasil dikembangkan merupakan tempat bagi mahasiswa untuk melakukan aktivitas pada materi turunan. Kegiatan-kegiatan tersebut mencakup menyelesaikan masalah yang disajikan, hingga pada penemuan konsep yang diinginkan. Berdasarkan hasil kajian produk yang telah direvisi di atas, maka saran yang dapat diberikan dari penelitian ini adalah sebagai berikut.

a. Perangkat yang dikembangkan ini dapat digunakan untuk mengembangkan penalaran matematis mahasiswa. Kepada para peminat yang ingin mengimplementasikannya maka dapat memodifikasi indikator penalaran matematis sesuai kebutuhannya.

b. Perangkat RP dan LKM dapat digunakan dengan memperhatikan materi pembelajaran, agar mahasiswa termotivasi dan tertarik dalam mengikuti pembelajaran di kelas. Selain itu perlu penyiapan RP dan LKM yang sesuai dengan model pembelajaran yang diinginkan. 


\section{Daftar Pustaka}

Dewi, Ni Wayan Dian Permana, Prof Dr I. Gusti Putu Suharta, and Prof Dr I. Made Ardana. 'PENGEMBANGAN PERANGKAT PEMBELAJARAN MATEMATIKA DENGAN PENDEKATAN SCIENTIFIC BERORIENTASI TEKNOLOGI INFORMASI DAN KOMUNIKASI UNTUK MENINGKATKAN KEMAMPUAN PEMECAHAN MASALAH DAN PENALARAN SISWA'. Jurnal Pendidikan Matematika 3, no. 1 (16 July 2014). http://pasca.undiksha.ac.id/ejournal/index.php/JPM/article/view/1365.

Goos, Merrilyn. 'Learning Mathematics in a Classroom Community of Inquiry'. Journal for Research in Mathematics Education 35, no. 4 (July 2004): 256-91.

Hudojo, Herman. Pengembangan Kurikulum Dan Pembelajaran Matematika. Malang: Universitas Negeri Malang Press, 2005.

Krulik, Stephen, Jesse A Rudnick, and Eric Milou. Teaching Mathematic in the Middle School. USA: Pearson, 2003.

Lynch, Kathleen, and Jon R Star. 'Views of Struggling Students on Instruction Incorporating Multiple Strategies in Algebra I: An Exploratory Study' 45, no. 1 (January 2014): 6-18. doi:10.5951/jresematheduc.45.1.0006.

Maimunah. 'Model Pembelajaran Matematika Untuk Meningkatkan Kemampuan Penalaran Matematika Siswa', November:141-53. Sidoarjo: Universitas Muhammadiyah, 2013.

Nieveen, Nienke. 'Educational Design Researsh: An Introduction'. In $A n$ Introduction to Educational Design Research, 89-102. Shanghai: Netzodruk,

n.d. http://www.slo.nl/downloads/2009/Introduction_20to_20education_2 0design_20research.pdf/download.

Plomp, Tjeerd. 'Educational Design Researsh: An Introduction'. In $A n$ Introduction to Educational Design Research, 9-36. Shanghai: Netzodruk, 2013. http://www.slo.nl/downloads/2009/Introduction_20to_20education_2 0design_20research.pdf/download.

Rahmadi, Furdan. 'Pengembangan Perangkat Pembelajaran Berbasis Pemecahan Masalah Berorientasi Pada Kemampuan Penalaran Dan Komunikasi Matematika'. PYTHAGORAS: Jurnal Pendidikan Matematika 10, no. 2 (11 December 2015): 137-45. doi:10.21831/pg.v10i2.9133.

Rochmad. 'Pengembangan Model Pembelajaran Matematika Beracuan Konstruktivisme Yang Melibatkan Pola Pikir Induktif-Deduktif Untuk Siswa Smp/Mts'. Universitas Negeri Surabaya, 2009.

Sa'dijah, Cholis. 'Pengembangan Model Pembelajaran Matematika Beracuan Konstruktivisme Untuk Siswa SMP'. Mathedu Jurnal Pendidikan Matematika. 1 (2) 1, no. 2 (July 2006): 109-22.

Scusa, Toni, and Yuma. Five Processes of Mathematical Thinking: Math in the Middle Institute Partnership. Lincoln: University Of Nebraska, 2008.

Slavin, Robert E. Psikologi Pendidikan Teori Dan Praktek. Jakarta: PT. Indeks, 2008. 